\title{
Anticancer activity of botanical compounds in ancient fermented beverages (Review)
}

\author{
P.E. McGOVERN ${ }^{1}$, M. CHRISTOFIDOU-SOLOMIDOU ${ }^{2,3}$, W. WANG $^{4}$, \\ F. DUKES ${ }^{2}$, T. DAVIDSON ${ }^{1}$ and W.S. EL-DEIRY ${ }^{4}$ \\ ${ }^{1}$ Biomolecular Archaeology Laboratory, University of Pennsylvania Museum of Archaeology and Anthropology;
${ }^{2}$ Pulmonary, Allergy and Critical Care Division, ${ }^{3}$ Center of Excellence in Environmental Toxicology (CEET), and
Division of Hematology and Oncology, University of Pennsylvania School of Medicine, Philadelphia, PA 19104, USA
}

Received February 24, 2010; Accepted April 15, 2010

DOI: 10.3892/ijo_00000647

\begin{abstract}
Humans around the globe probably discovered natural remedies against disease and cancer by trial and error over the millennia. Biomolecular archaeological analyses of ancient organics, especially plants dissolved or decocted as fermented beverages, have begun to reveal the preliterate histories of traditional pharmacopeias, which often date back thousands of years earlier than ancient textual, ethnohistorical, and ethnological evidence. In this new approach to drug discovery, two case studies from ancient Egypt and China illustrate how ancient medicines can be reconstructed from chemical and archaeological data and their active compounds delimited for testing their anticancer and other medicinal effects. Specifically, isoscopoletin from Artemisia argyi, artemisinin from Artemisia аппиа, and the latter's more easily assimilated semi-synthethic derivative, artesunate, showed the greatest activity in vitro against lung and colon cancers. In vivo tests of these compounds previously unscreened against lung and pancreatic cancers are planned for the future.
\end{abstract}

\section{Contents}

1. Introduction

2. Ancient Egyptian herbal wine, ca. 3150 B.C.

3. Ancient Chinese herbal wine, ca. 1050 B.C.

4. Methodological approach

5. In vitro studies of active compounds: materials and methods

6. Discussion and conclusions

Correspondence to: Dr Patrick E. McGovern, Biomolecular Archaeology Laboratory, University of Pennsylvania Museum of Archaeology and Anthropology, 3260 South Street, Philadelphia, PA 19104, USA

E-mail: mcgovern@sas.upenn.edu

Key words: ancient medicine, artemisinin, artesunate, biomolecular archaeology, herbal wine, HCT116 colon adenocarcinoma, isoscopoletin, Lewis lung carcinoma, p53, Traditional Chinese Medicine

\section{Introduction}

Ethnohistorical accounts and modern ethnological practices of peoples around the world provide a rich source of potential natural products (animal, plant, and mineral) for discovering lead molecular structures for new drugs. We have only to consider the alkaloid quinine, derived from the bark of South American trees and shrubs (Cinchona spp), which was recognized as effective against malarial fever by native Peruvians since at least the 17 th c. (1). The compound was isolated in 1820, and it saved countless lives in the following century and a half. Similarly, references in ancient Mesopotamian, Egyptian, and Greek texts provided the impetus for the isolation and eventual modification of salicylic acid from willow tree bark (Salix spp.) in the 19th century; acetylsalicylic acid (aspirin) is today the most widely used pharamaceutical palliative.

Another natural product, which has been extensively investigated by one of the co-authors (M. ChristofidouSolomidou), is flaxseed, derived from the flax plant (Linum usitatissimum). This annual herb, one of the founder plants of the Near Eastern 'Neolithic Revolution', became an important part of the ancient Egyptian pharmacopeia, and is still important in the traditional medicine of the region. The high percentage of $\alpha$-linolenic acid, an $\omega-3$ fatty acid, and lignans in flaxseed have been shown to be protective against breast and colon cancer $(2,3)$. More recently, flaxseed was shown to possess potent antioxidant and anti-inflammatory properties (4-6). Encouraging in vitro and in vivo findings have led to the initiation of several clinical trials using flaxseed and flaxderived lignans in the USA, Europe and China.

In North America, European explorers observed the native peoples steeping Canada yew needles (Taxus canadensis) to make a tea for treating arthritis (7). A National Cancer Institute study in 1967 showed that one compound in yew bark, paclitaxel, is a strong inhibitor of a host of cancers, especially ovarian and breast. Under the trademark TAXOL, this drug has since become the largest selling anticancer medicine in the world.

Many other successes of translating a traditional, natural remedy into an efficacious drug might be cited $(8,9)$. For example, the development of the podophyllin class of anti- 
cancer drugs grew out of native American observations that mayapple roots (Podophyllum peltatum) could mitigate skin cancer, and the anti-inflammatory and anticancer drugs triptolide and celastrol were a direct result of experimentation with the 'thunder god vine' (Trypterygium wilfordii Hook F.) of Traditional Chinese Medicine (TCM).

As these several parade examples show, plant exudates (including resins and nectar) and other structures (flowers, roots, leaves, etc.) have figured importantly in drug discovery. Yet, it has been estimated that only about 5,000 plant species (1.5-2\%) out a total of 250,000-300,000 world-wide have been exhaustively studied for possible medical benefits (10). Overwhelmingly, their use in traditional medicine was the main criterion for their selection (11). This approach makes good sense, since it is a daunting task to construct large libraries of de novo synthetic compounds and test them for their medicinal effects. Nature has already carried out combinatorial chemistry on a vast scale to produce compounds, particularly secondary metabolites, which serve to ward off disease and noxious organisms, to prevent premature death (e.g., by cancer), and to promote growth and other physiological functions (12).

When the abundant productivity of nature is coupled with human observation and experimentation by trial and error over hundred of thousands if not million of years, stretching back into the Palaeolithic period, then the prospects for drug discovery become even greater. Our human and hominid ancestors had a large incentive for exploring the world around them for possible remedies against diseases and physical ailments. Lacking modern synthetic medicines and suffering from maladies of all kinds that resulted in infant death and short life spans, their only recourse was to 'experiment' with the plants, other animals, minerals, and microorganisms. Even if the latter were microscopic, their effects might be visually apparent, as when the fermentation of sugary concoctions is accompanied by the evolution of carbon dioxide. Their experimentation was not the rigorous scientific testing that we demand today, but if a remedy had no observable practical effect, we might expect such a false-positive eventually to be culled out over thousands of years. On the other hand, superstitions, misguided religious injunctions, or unfounded psychological notions might creep into a tradition over time (e.g., submerging a rhinoceros horn or bull's penis in a modern Chinese wine to convey its strength or other sympathetic attribute).

Efficacious medicines might well have been discovered during innovative periods when traditional approaches were open to new ideas, such as the Neolithic Revolutions in which numerous plants were domesticated in 'centers of origin' around the world, including east Asia, the Near East, the Andes and Amazonia in South America, southern Mexico, the African Sahel, and New Guinea (13). Depending on the vagaries of human oral and written traditions, as well as cultural collapse and destruction by natural and manmade calamities, any 'discovery' might subsequently be lost.

Ancient textual, ethnological, and ethnohistorical pharmacological approaches provide important means to discover the medical 'database' of our ancestors. However, with the advent of biomolecular archaeology over the past 20 years, an independent method is now available, which avoids the ambiguities and accretions of later tradition embedded in written texts and oral accounts. By analyzing contemporaneous organic residues inside ancient containers, key natural products and organic compounds of potential medicinal value can be directly detected. Several case studies are presented to illustrate this potentially very effective approach, along with follow-up testing of important medicinal compounds to date.

\section{Ancient Egyptian herbal wine, ca. 3150 B.C.}

Fermented beverages, made from sweet fruits, honey and saccharified cereals, were likely discovered and utilized by humans at a very early date (14). All animals - from the fruit fly to the elephant - derive a significant amount of their energy from sugar resources. Alcohol from a fermenting natural product leads animals to sugar by putting up pungent plumes, besides providing its own metabolic resource (15). Indeed, based on ancient hominid dentitions and the diet of our nearest genetic relative - the chimpanzee - plants and fruits probably accounted for some $75-90 \%$ of ancient humans' food intake. In the warm tropical climate of sub-Saharan Africa where the species emerged, these high-sugar resources can achieve alcoholic contents of $5 \%$ or more by natural fermentation.

Alcoholic beverages conferred many advantages to the human species when consumed in moderation. It was the universal drug up until the advent of modern medicine, since its health benefits were obvious - alcohol relieved pain, stopped infection, and killed microorganisms and parasites in tainted water. Alcoholic beverages also served as social 'lubricators', facilitating social communication and easing the difficulties of everyday life. As a mind-altering substance, it entered into religious practice. But from a medical standpoint, the alcohol in fermented beverages enabled plant compounds, whether from fruits, tree resins, flower nectars, roots, herbs or spices, to be taken into solution (16). 'Medicinal wines' and external salves, with anesthetic, antimicrobial, and psychotropic properties are recorded in later pharmacopeias from around the world. By using biomolecular archaeological techniques, humankind's first medical forays can be pushed back into prehistoric times.

In a recent study (17), a residue sample from inside a jar (Fig. 1) belonging to one of the first rulers of ancient Egypt, Scorpion I of Dynasty 0, was analyzed. The jar was one of some 700 , stacked high in three chambers, of an exceptionally rich tomb (denoted U-j) at the site of Abydos (18) (Fig. 1).

Analysis by a variety of techniques [including Liquid Chromatography Tandem Mass Spectrometry and Headspace Solid Phase Microextraction (SPME) and Thermal Desorption (TD) Gas Chromatography-Mass Spectrometry (GC-MS)] showed that this jar and others had contained a grape wine. The wine, however, was not a pure varietal, which is the goal of many winemakers today. In addition to whole grapes and figs, a pine and/or terebinth tree resin had been added to the wine. Eight terpenoid compounds - linalool, camphor, borneol, L-menthol, $\alpha$-terpineol, carvone, thymol, and geranyl acetone provided further evidence that a range of herbs of Levantine origin, where the wine had been made and then exported to Egypt, were also added.

These herbs could be tentatively identified by a thorough search of the chemical literature using bioinformatics search engines (see Methodological approach, below). Species of 


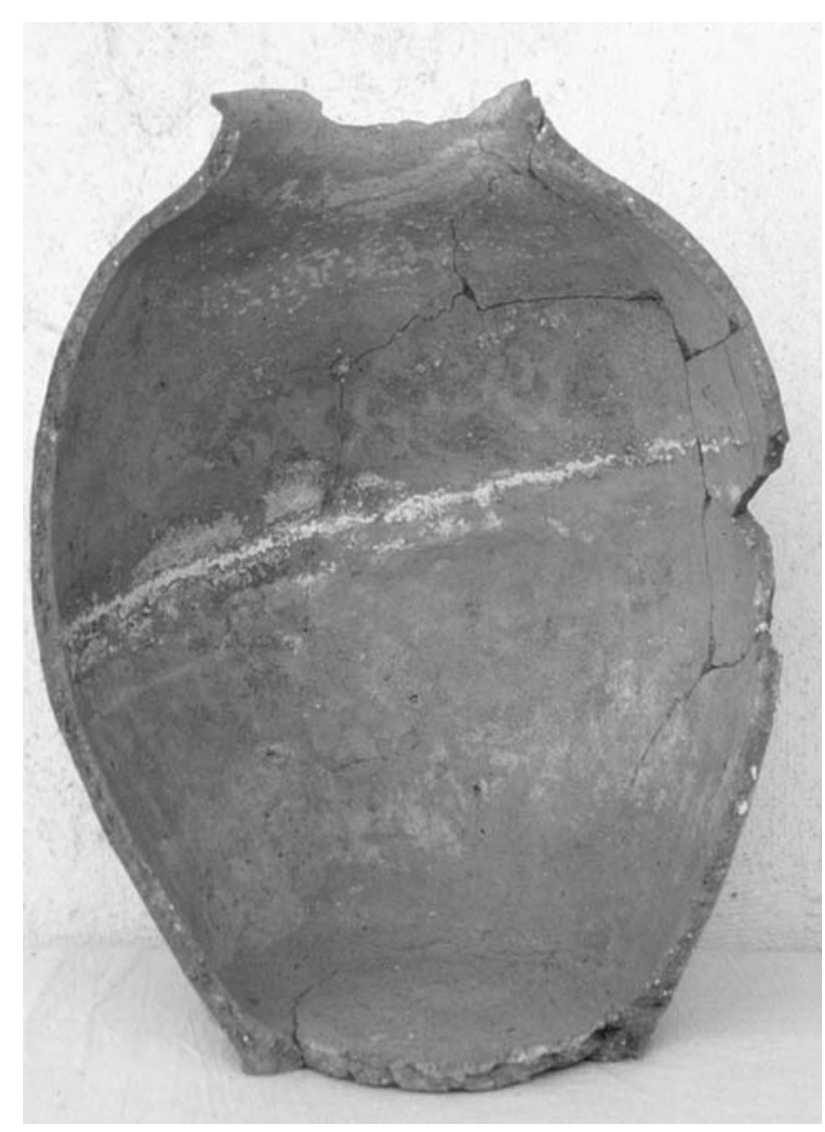

Figure 1. A yellowish residue, the accumulation of ancient organic materials from the upper surface of the grape wine that once filled the inside of jar no. 50 from the tomb (U-j) of Scorpion I at Abydos (Egypt), ca. 3150 B.C (Hartung 2001: cat. no.156, pls. 58: and 94:156). The residue, forming a circle around the vessel's interior, is slanted off from the horizontal, because the jar with its liquid was tilted in antiquity. Analyses showed that herbs including balm, coriander, mint, sage and many more were steeped in the wine, to which pine resin and figs were also added. Ht. of sherd $33.5 \mathrm{~cm}$. Photograph courtesy of German Archaeological Institute in Cairo.

ten botanical genera accounted for the most compounds savory (Satureja), wormwood/mugwort (Artemisia), tansy (Tanacetum), balm (Melissa), senna (Cassia), coriander (Coriandrum), germander (Teucrium), mint (Mentha), sage (Salvia), and thyme (Thymus/Thymbra). They were thus the most likely additives used individually or in combination.

At first, we were surprised to discover that the Scorpion I wine had been 'adulterated' with so many additives. A tree resin was the least surprising, since our analyses of numerous ancient residues from throughout the Middle East and Mediterranean over millennia has shown that a popular, widespread practice in antiquity was to resinate wine. Besides covering up off-tastes and aromas, tree resins contain antioxidant compounds which help to preserve the wine. Resinated wines were still being made in the Middle Ages, according to the extensive agricultural and medical compilations based on classical writings, collectively known as the Geoponica (19).

The finding of herbal additives in the Scorpion I wine, however, made us suspect that the Levantine winemakers and their Egyptian clients might well have had a more farreaching purpose in preparing and consuming such mixed beverages. Egypt has one of the most ancient and detailed materia medica in the world, based on archaeobotanical findings and literary traditions $(20,21)$. Papyri, dating back to the mid-12th Dynasty, ca. 1850 B.C., show that 'medicinal wines' were very important to the Egyptian 'physician' (swnw, the hieroglyphic word, is attested as early as Dynasty 3, ca. 2650 B.C.).

More than a thousand prescriptions are recorded in the ancient Egyptian medical papyri. Most numerous are those that list alcoholic beverages - wine and beer - as dispensing agents, and in which tree resins (terebinth, pine, frankincense, myrrh, fir, etc.) and numerous herbs (bryony, coriander, cumin, mandrake, dill, aloe, wormwood, etc.) are added ingredients. The plants and their exudates were macerated, mixed together, and steeped in these beverages; they were administered for specific ailments. Traditional Egyptian medicine today still uses many of the same formulations. Based on the continuity of Egyptian medicine over thousands of years, it is reasonable to project it further back into the past, to account for the biomolecular and archaeobotanical evidence from the Scorpion I wine jars.

After establishing the possible natural product additives to the Scorpion I wine, our next step was to search the available scientific literature for any active medicinal compounds reported for these ingredients. Our specific focus has been anticancer compounds, since our collaborative program at the University of Pennsylvania Medical Center is in this area. Because most of the numerous plant terms and diseases in the ancient Egyptian prescriptions cannot be translated or identified as yet, we cannot be certain which herb or other plant material is specifically associated with a given cancer. However, Egyptian morticians and physicians, who mummified the dead, would have had detailed anatomical knowledge of ancient internal and external cancers. Specific remedies were likely developed to treat such cancers. On this assumption and according to our in vitro screening of lung and colon cancers, the most promising anticancer compounds in the Scorpion I wine are luteolin found in (sage) and ursolic acid (a triterpenoid in thyme and other herbs). Ursolic acid causes cancer cell death under hypoxic conditions, which may warrant further investigation (see below).

\section{Ancient Chinese herbal wine, ca. 1050 B.C.}

To date, our earliest evidence of an alcoholic beverage from anywhere in the world, which might have been used medicinally, is from the Neolithic site of Jiahu in the Yellow River Valley of China, dating back to ca. 7,000 B.C. (22). Biomolecular archaeological analyses of pottery jars which contained the beverage showed that the ancient beverage had been formulated from rice, honey, a Chinese grape species, and hawthorn tree fruit. This finding is obviously of great interest for the history of Chinese medicine, which was already being written down in the earliest texts - the oracle bone inscriptions of the late Shang Dynasty (ca. 1200-1046 B.C.) and then continued to develop over the next three millennia to become TCM. In recent decades, the latter has been put on a much more solid scientific basis (e.g., 23,24). Since we have not yet analyzed the extracted residues from the Jiahu jars by SPM or TD GC-MS, it is not known whether any herbs or spices, which might have anticancer or other medicinal 
properties, were added to the ancient mixed beverage. Other than several well-known and studied anti-oxidant compounds from grape (e.g., resveratrol) and hawthorn fruit, our survey of the literature did not reveal any additional active anticancer compounds to be screened.

By Shang Dynasty times, however, herbs were clearly part of an already highly specialized medicinal wine 'industry'. One wine (chang) was specifically denoted as herbal wine in the oracle bone inscriptions. Officials in the Shang palace administration were charged with making the beverages, which the king inspected. Our TD GC-MS analysis of liquid, amazingly still contained inside a lidded bronze jar (Fig. 2) from the Changzikou Tomb in Henan Province (ca. 1050 B.C., contemporaneous with the oracle bone inscriptions), illustrates what information can be gleaned via biomolecular archaeology (22). The tight lid on the jar accounts for the liquid having not evaporated: it had corroded to the neck, hermetically sealing off the jar's contents until the tomb was excavated thousands of years later.

The analysis revealed that two aromatic compounds camphor and $\alpha$-cedrene - were present in the ancient beverage, in addition to benzaldehyde, acetic acid, and short-chain alcohols characteristic of rice and grape wines. Stable ${ }^{13} \mathrm{C}$ and ${ }^{15} \mathrm{~N}$ isotope measurements identified the beverage as ricebased. Based on a thorough search of the chemical literature, camphor and $\alpha$-cedrene might have originated from a specific tree resin [China fir = Cunninghamia lanceolata $($ Lamb.) Hook.]; a flower of the chrysanthemum family; or an aromatic herb, specifically Artemisia annua and/or A. argyi in the wormwood/mugwort genus [N.B.: Shin (25) now reports $\alpha$-cedrene to be present in A. annua (26)]. If an Artemisia species explains the presence of camphor and $\alpha$-cedrene, then the plant's leaves had probably been steeped in the rice wine, as is still done in TCM. An open vat found in the Changzikou Tomb, which was filled with aromatic Osmanthus fragrans (tea olive) leaves and held a ladle, pointed to this method of preparation of the ancient beverage, which is still popular today for making flavored or medicinal tisanes and drinks (Fig. 2).

Of the possible ingredients and additives identified in the Changzikou wine, the two species of Artemisia stood out because of their long-standing importance in TCM up to the present day. Both A. annua (wormwood) and A. argyi (mugwort), usually equated in TCM with Qinghao and Ai Ye respectively (27), were cited in the earliest Chinese medical prescriptions, the Mawangdui tomb texts dating to 168 B.C. (28). There, Qinghao is prescribed for female hemorrhoids and as a sexual tonic, being mixed with other herbs, including cinnamon and ginger, and administered in boiled urine. Ai Ye was also administered in a grass broth as a sexual stimulant, and was burned with willow fungus to treat hemorrhoids. It later was used in the very important practice of moxibustion, in which $A$. argyi leaves were burned, often on the tips of acupuncture needles, and applied to the key points on the body. The monumental 'Compendium of Materia Medica' by Li Shizen, published in 1596 A.D., attests to the long medicinal use of Artemisia herbs in TCM when it cites Ge Hong's (284-364 A.D.) 'Handbook of Prescriptions for Emergency Treatment.' As for the highly developed ancient Egyptian pharmacopeia, it is likely that ancient Chinese
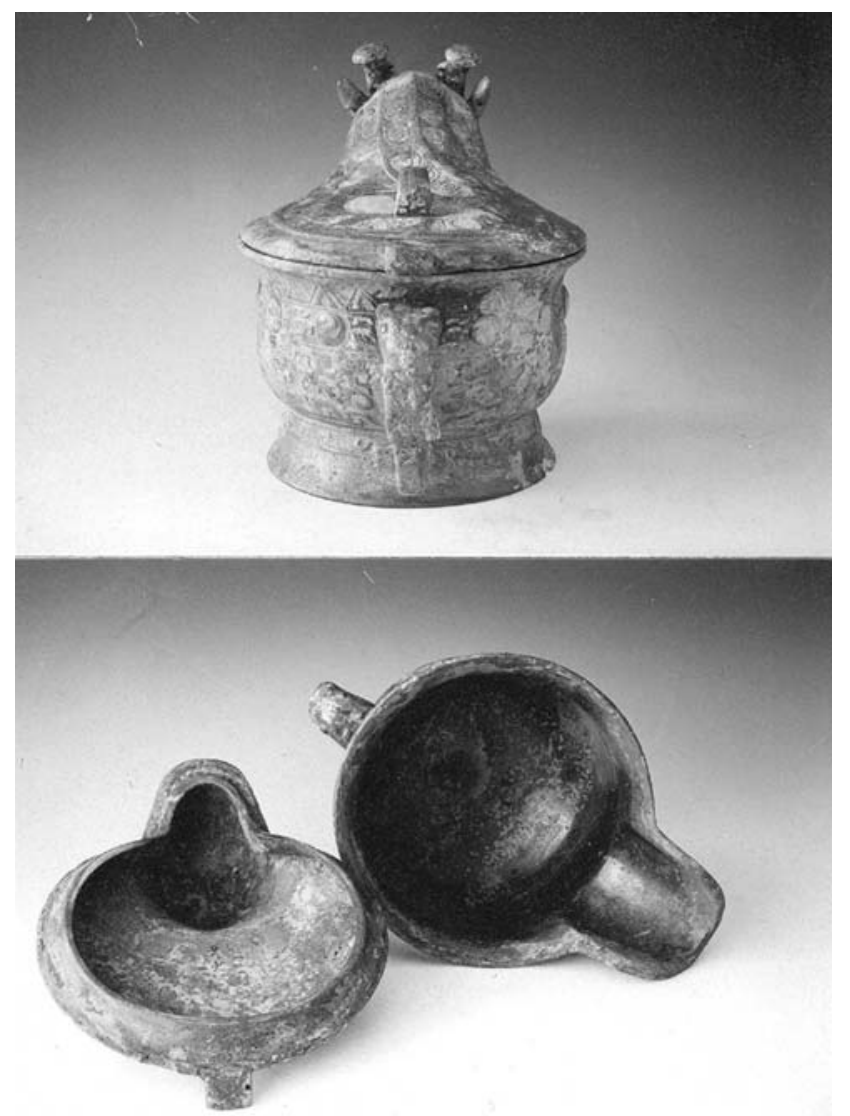

Figure 2. Bronze уои jar (upper, lid in place; lower, lid removed), which contained an herbal rice wine that was still liquid when it was recovered in 1998 from the Changzikou Tomb, dated ca. 1050 B.C., in Luyi Country, eastern Henan Province. The biomolecular archaeological results pointed to Artemisia argyi as a key medicinal additive. Photograph courtesy of Z. Zhang and Institute of Cultural Relics and Archaeology of Henan Province.

physicians had detailed anatomical knowledge of the human body, including many different kinds of cancer, and would have developed remedies targeted at those cancers.

Artemisinin, a sesquiterpene lactone derived from A. annua, proved to be the most important active compound found in our extensive literature search of the species and as confirmed by our in vitro cell line tests against colon and lung cancers (below). Its semi-synthetic analogue, artesunate, was even more effective against colon cancer (29) and many others, including Kaposi's sarcoma (30), uveal melanoma (31,32), hepatoma (33) and ascitic liver tumor (34), ovarian cancer (35), pancreatic cancer (36), neuroblastoma (37), and myeloid leukemia (38). Artesunate is also more readily absorbed by the body than artemisinin, and has lower toxicity. Both compounds have other medicinal effects against malaria, bacterial and viral infections, and hepatitis B and C (39).

Because of the importance of A. annua in TCM, it was chosen during the Vietnam War as a prospective herb for testing against malaria $(32,40)$. The anticancer properties of the herb's principal active compound, artemisinin, were subsequently discovered, and still remain to be fully elucidated (41-53). Efferth and colleagues (54) have proposed that artemisinin's anticancer mechanism of action is via the endoperoxide linkage of the compound. The latter opens up and creates free radicals that oxidatively react with intracellular 
components, leading to apoptosis of cancer cells. Intracellular ferrous iron has been implicated in this reaction.

Another active compound which showed promise against cancers in our in vitro screening (below) - isoscopoletin, a coumarin flavone - has thus far been obtained only from $A$. argyi in this genus. Other researchers (55) have documented this compound's cytotoxicity against leukemia cells, likely by inhibiting the activity of farnesyl protein transferase (FTPase). Both A. argyi and annua are sources of borneol, a monoterpene, which also exhibited some anticancer activity in our studies.

\section{Methodological approach}

Because of the novelty of using biomolecular archaeology to target potential compounds for anticancer testing, some additional explanation of its prospects and limitations is helpful.

Our ability to identify compounds in an ancient residue is only as good as the instrumentation available, which is constantly improving. Moreover, how well the residue was preserved, which depends on its archaeological context and environmental factors, is crucial in detecting any intact organics or their degradation products.

Once the compounds in the ancient residue have been established, bioinformatics tools - SciFinder Scholar, the Kirk-Othmer Encyclopedia of Chemical Technology, Dr Duke's Phytochemical and Ethnobotanical Databases, the chemical database of the Amber Research Laboratory of Vassar College, etc. (56-59) - are employed to discover the original natural products. Marker or fingerprint compounds, which are characteristic of specific plants, are most important. Sometimes a single compound, such as tartaric acid which uniquely points to the Eurasian grape (Vitis vinifera) in the Middle East (17), will be found. Other samples may yield many compounds, none of which is sufficient by itself to isolate the natural product, but together may provide the probable plant(s) according to Occam's razor or rule, viz., the simplest, most straight-forward explanation is often the right one.

Our interpretation of the biomolecular archaeological data greatly depends on which natural products have thus far been analyzed and published. Even with the powerful bioinformatics tools now available, the potential data set of natural product chemistry is much larger, and will continue to expand as more plants are analyzed and more sensitive techniques become available. Moreover, the compounds reported are often limited to specific chemical classes, and are compromised by many other factors, including the plant part tested, collection season, extraction method, experimental technique, and analytical conditions. This problem is underlined by A. аnnua, which has been extensively analyzed because of its anti-malarial properties, and A. argyi, which is less well-characterized chemically. Thus, the interpretation of the biomolecular archaeological data is constantly being refined.

Our decision of which plants to test for possible anticancer compounds is also dependent on known and published natural product chemistry, which we intensively search using bioinformatics tools. This approach obviously seeks to discover compounds from ancient plants which have already been shown to have anticancer or other medicinal effects. It may or may not lead to the discovery of new anticancer compounds.
It should be noted, however, that even if artemisinin from A. annua had not already been shown to have anticancer properties, this approach would have led us to test and discover this fact.

In the future, we plan to incorporate independent extraction and targeted analysis into our research protocol. This approach will entail obtaining fresh samples from different parts of the plants which the biomolecular archaeological data indicate are present in the ancient residues. Since composition can vary by geographic area, season of the year, etc., multiple samples will need to be extracted and tested. In addition to conventional steam distillation, other methods (including supercritical fluid and microwave extraction coupled to SPME as applied to Artemisia species $(29,60,61)$ should be employed. Combined with solvents ranging in polarity and more sensitive analytical techniques, the prospects for discovering new anticancer compounds will then be greatly enhanced.

Independent extraction and isolation of compounds from fresh botanical materials will also obviate the present need to restrict our anticancer testing to high-purity, commercial compounds.

\section{In vitro studies of active compounds: materials and methods}

Based on the biomolecular archaeological results for the ancient Egyptian and Chinese fermented beverages, coupled with our extensive literature search, the following potentially active, high-purity (>97\%) compounds were tested: i) luteolin (Sigma L9283), present in Salvia; ii) ursolic acid (Fluka 89797), present in Thymus; iii) artemisinin (Aldrich 361593), present in A. аnnua; iv) artesunate (AvaChem Scientific 1562 and Sigma A3731), a derivative of artemisinin; v) borneol (Fluka 15599), present in A. argyi; vi) bornyl acetate (Sigma W21590-2), present in A. argyi; vii) isoscopoletin (ChromaDex ASB-00009570-010), present in A. argyi; and viii) scopoletin (Sigma S-2500), present in A. argyi. The staining agent, 3(4,5-dimethylthiazol-2-yl)-2,5-diphenyltetrazolium bromide (MTT), was obtained from Promega (G5430).

For the in vitro tests in Wafik El-Deiry's laboratory, HCT116 colon adenocarcinoma cell lines, expressing a firefly luciferase p53 reporter PG13-luc (62), were challenged by the potentially active compounds. Each compound was first tested at standard concentrations $(25,50,100,200,400$, and $800 \mu \mathrm{M}$ ) for 12 and $24 \mathrm{~h}$. If activity was observed, lower concentrations of that compound (down to $0.10 \mu \mathrm{mol}$ ) for periods up to $72 \mathrm{~h}$ were tested. All compounds were dissolved in a stock solution to a concentration of $100 \mathrm{mM}$ in DMSO. Standard concentrations $(0.2$ and $0.4 \mu \mathrm{g} / \mathrm{ml})$ of adriamycin provided a comparison for any cytotoxic effects. The luciferase activity was imaged by a Xenogen IVIS imaging system.

Cell proliferation tests were then performed in $\mathrm{M}$. Christofidou-Solomidou's laboratory that were focused only on artemisinin and artesunate, which had shown greatest promise in the p53 induction experiments. Murine Lewis lung carcinoma (LLC) cells were cultured in Dulbecco's modified Eagle's medium (DMEM) containing 10\% heatinactivated fetal bovine serum (FBS) at $37^{\circ} \mathrm{C}$ in a humidified atmosphere of $5 \% \mathrm{CO}_{2}$. LLC cells were added to a 96-well plate at a density of 5,000 cells/well and allowed to adhere 

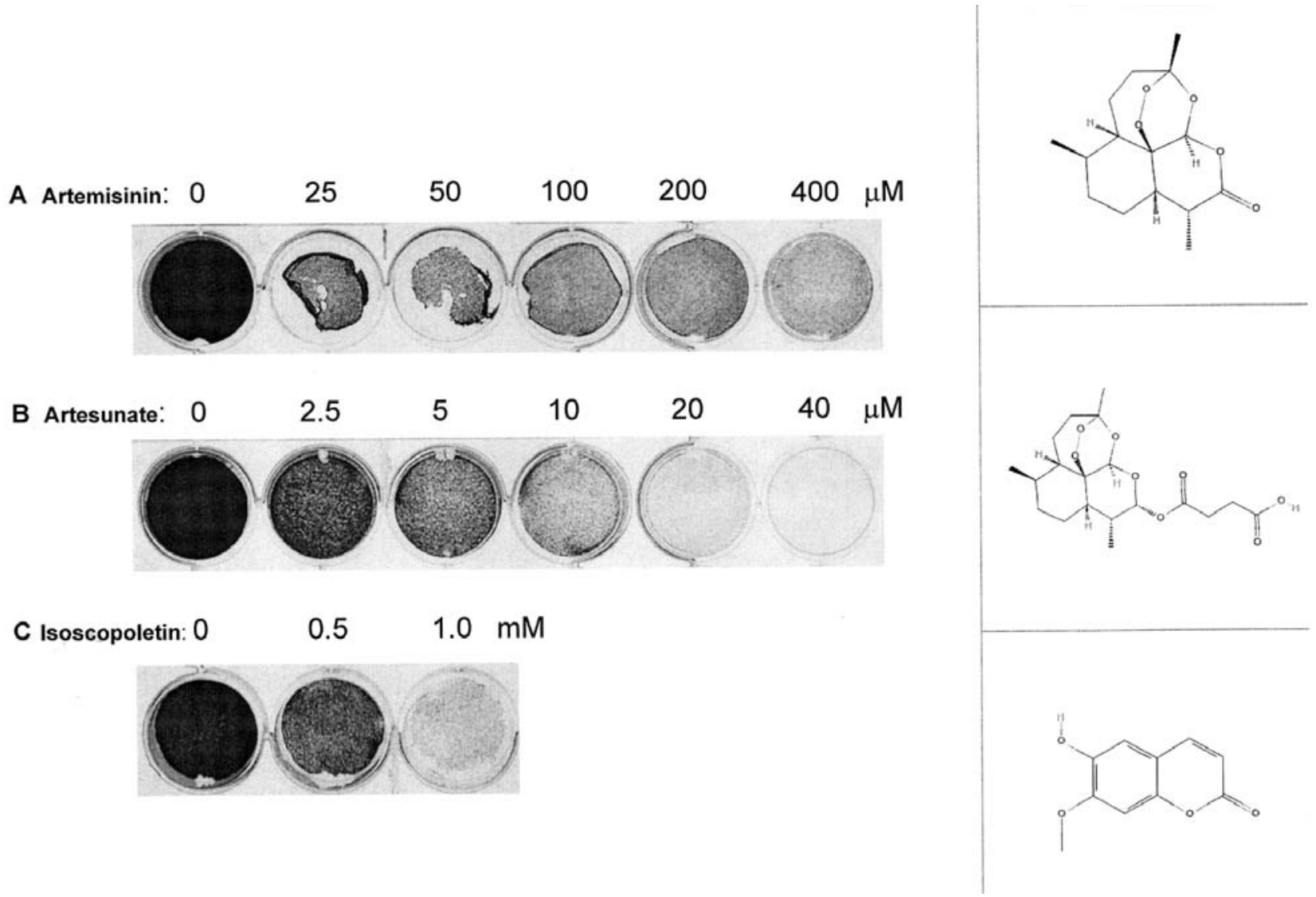

Figure 3. Activity of p53 against HCT116 colon adenocarcinoma cell lines for two active compounds (artemisinin and isoscopoletin) in Chinese Artemisia species, which were attested in an ancient Chinese wine (Fig. 2), and for artesunate, a derivative of artemisinin. Their molecular structures are shown to the right.

overnight. Cells were first treated with various concentrations of artemisinin and artesunate or the solvent vehicle dimethyl sulfoxide (DMSO) and incubated for 24, 48 and $72 \mathrm{~h}$, following which they were assessed for their proliferation using a routine MTT assay (63). Briefly, $100 \mu 1$ of $0.5 \mathrm{mg} / \mathrm{ml}$ MTT solution was added to each well, the cells incubated for $2 \mathrm{~h}$ at $37^{\circ} \mathrm{C}$, and the optical density measured using a microplate reader (Bio-Rad 680). All conditions were run in triplicate. Two series of experiments were carried out: i) concentrations of $25,50,100,200,400,500$ and $800 \mu \mathrm{M}$ of artemisinin and artesunate were added only once to the cells, at the start of the experiment, and ii) lower doses of artesunate $(1,2,4,8,25,50,100$ and $200 \mu \mathrm{M})$ were added to the cells each day of the experiment for 1-, 2-, or 3-day periods.

\section{Discussion and conclusions}

Biomolecular archaeological evidence, which is increasingly retrievable from ancient containers using microchemical techniques, points to a long history of medicinal and anticancer remedies that were tried, tested, and sometimes lost throughout the millennia since the human species emerged in Africa and spread out across the planet starting around 100,000 years ago. Our ancestors might well have discovered empirically some of the most potent and medicinally effective plants in their environments, especially in periods of experimentation as epitomized by the Neolithic Revolutions beginning 10,000 years ago, after the end of the last Ice Age. Plants, including herbs, tree resins, and other organics were ideally dissolved in and dispensed by ancient fermented beverages, such as wine and beer (14).

Two case studies, one detailing a biomolecular archaeological study of the earliest grape wine yet found in ancient Egypt (ca. 3150 B.C.) and the other describing the chemical findings of a liquid recovered inside a Shang Dynasty stoppered bronze vessel (ca. 1050 B.C.), show how the new field of bioarchaeological oncology can significantly broaden and contribute to traditional ethnopharmacological approaches. The latter are necessarily limited to traditional practices, such as TCM, or are based on relatively recent oral and written traditions, which can be variously interpreted.

The biomolecular archaeological evidence is derived directly from residues of ancient vessels, sometimes thousands of years old, and is contemporaneous with its medicinal use. Although one cannot always be certain that a specific organic additive to an alcoholic beverage was originally intended as a medicinal or anticancer agent, this can be reasonably inferred, especially if there exists a strong later textual tradition which can then be projected back into the past. Ancient Egypt and China are prime examples of cultures in which a long pharmacological history provides excellent supporting evidence. In some instances, the same plants which have been identified by biomolecular archaeological analyses 
A

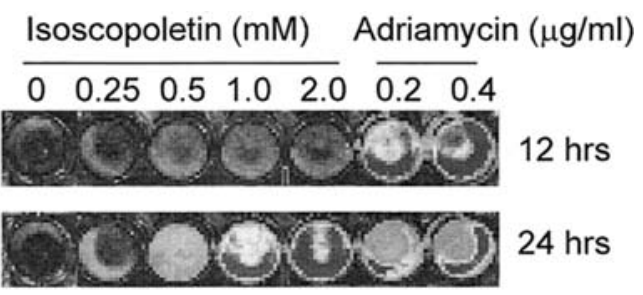

B

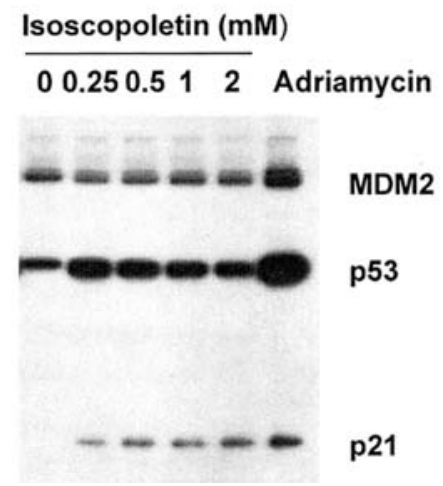

Figure 4. The relatively greater activity at longer time periods of isoscopoletin versus adriamycin, a standard anti-cancer agent, is shown by p53 luciferase activity (A) and Western blot analysis (B) against HCT116 colon adenocarcinoma cell lines.

(e.g., A. апnua and A. argyi) are specifically mentioned in their earliest pharmacopeias. By taking advantage of careful observations by our human ancestors, albeit by simple trial and error, discovering lead structures for combinatorial exploration can be streamlined and made more efficient.

As a first test in screening the possible active compounds, in vitro tests against two cancer cell lines (viz., HCT116 colon adenocarcinoma and Lewis lung carcinoma) were carried out. While Wafik El-Deiry's laboratory focused on whether p53 molecular activity was induced in the tumor cells by any of the potentially active compounds in the ancient fermented beverages, the tests in M. Christofidou-Solomidou's laboratory were directed towards assessing the potency of the two most promising compounds, artemisinin and artesunate.

The protein $\mathrm{p} 53$ serves as a genome guardian and plays a fundamental role in tumorigenesis, tumor progression, and therapeutic response of tumors (64). It functions mainly as a transcription factor by binding to specific DNA sequences and by transactivating or repressing a large and ever-increasing group of target genes. The latter in turn regulate the pathways of cell-cycle arrest, apoptosis and DNA repair, thereby maintaining a dynamic equilibrium between cell growth, arrest and death under stressful conditions, including DNA damage, hypoxia, deficiency of growth factors or nutrients, etc (Fig. 3).

The active compounds detected by the $\mathrm{p} 53$ studies included artemisinin, artesunate, borneol, isoscopoletin, and ursolic acid, with inhibition effects on tumor growth ranging in concentration from micromolar to millimolar amounts. Although artesunate, and to a lesser extent artemisinin, are most active against HCT116 colon adenocarcinoma (Fig. 3), isoscopoletin (Fig. 3C) was of particular interest, since it induces p53 transcriptional activity greater than that by the well-established
DNA anti-damage agent, adriamycin (Fig. 4A), after a 24-h treatment. To verify the p53 results for isoscopoletin, a Western blot analysis (Fig. 4B) was used to visualize p53 protein levels and one of its targets, p21, a potent cyclin-dependent kinase inhibitor which was identified as the first p53 target (65). As can be seen in the figure, p53 protein is up-regulated after isoscopoletin treatment, inducing an increase in p21. On the other hand, MDM2, another p53 target that serves as a negative regulator, is slightly reduced. It may be hypothesized that isoscopoletin is using this mechanism of p53 activation to enhance its anticancer efficacy, whereas adriamycin, which induces more MDM2, operates via the usual p53 DNA damage-signaling pathway (Fig. 4).

Fig. 5 illustrates how ursolic acid, found in species of thyme, is much more effective against colon cancer under low-oxygen conditions (hypoxia) than normal atmospheric conditions (normoxia). This compound inhibits tumor growth at a concentration of around $50 \mu \mathrm{M}$ under normoxia; much lower concentrations of 1-10 $\mu \mathrm{M}$ are sufficient to achieve the same result under hypoxia. Tumor cells, especially those which are solid and dense, survive and proliferate under hypoxia. A strategy in anticancer therapy is to counteract this property of tumor cells. It may be hypothesized that the anticancer potency of ursolic acid is related to mechanisms operating under hypoxia (Fig. 5).

The dose response results of artemisinin and artesunate against murine LLC cells by M. Christofidou-Solomidou's laboratory bore out the p53 findings. As shown in Fig. 6A and $\mathrm{B}$, artemisinin treatment slightly inhibited cell growth and then only in high concentrations while artesunate significantly inhibited growth of the tumor cells with as low as $25 \mu \mathrm{M}$. Cell viability of lung carcinoma cells in response to $25 \mu \mathrm{M}$ artesunate was 62 and $35 \%$ at 24 and 48 h, respectively $(\mathrm{p}<0.05)$; artemisinin treatment was nearly the same as the control. In the second set of experiments (Fig. 6C and D), even lower doses of artesunate showed it to be a much more potent inhibitor of cancer cell proliferation than artemisinin. Specifically, artesunate caused a low 16 and $14 \%$ cell viability at 48 and $72 \mathrm{~h}$, respectively when given at $25 \mu \mathrm{M}$ versus a comparable viability range of 12 and $18 \%$ at 48 and $72 \mathrm{~h}$ respectively for artemisinin at a much higher concentration of $800 \mu \mathrm{M}$. These data show that both artesunate and artemisinin treatments resulted in a concentration-dependent inhibition of cell growth in Lewis lung carcinoma cells, but that artesunate was $>30$ times as effective (Fig. 6).

Based on these results, we propose in vivo and clinical studies of one derivative compound from A. annua in particular: artesunate. As already known from in vivo mouse studies of other cancers, we plan to test this compound for its clinical efficacy against lung and pancreatic cancer. To date, the effectiveness of artesunate against these specific cancers has not been determined.

As more and more plants from around the world are chemically analyzed, large gaps in databases will be filled in, and as microchemical methods improve, the prospects for biomolecular archaeological oncology will grow. We are just at the beginning of 'Digging for Drug Discovery,' as this new multidisciplinary approach to ancient ethnopharmacology expands and matures. 
Ursolic acid $(\mu \mathrm{M})$
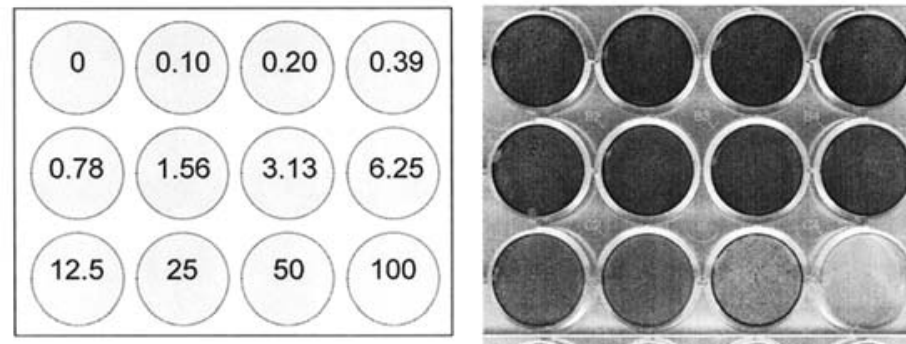

Normoxia: 4 days

(medium changed

after 2 days)

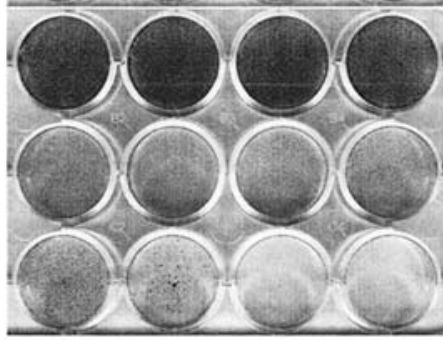

Hypoxia: 2 days

Change medium

Normoxia: 2 days

Figure 5. Ursolic acid, derived from thyme and attested in an ancient Egyptian wine (Fig. 1), is seen to be much more effective against colon cancer under hypoxia than normoxia.

A
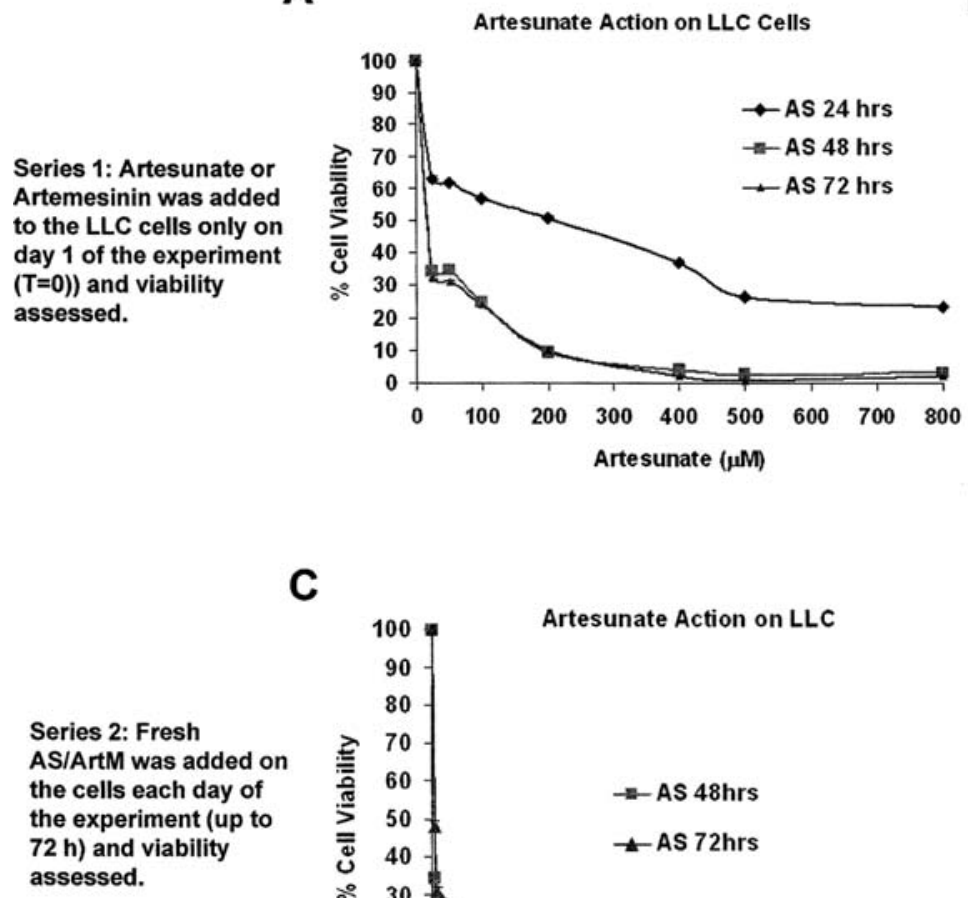

C

B

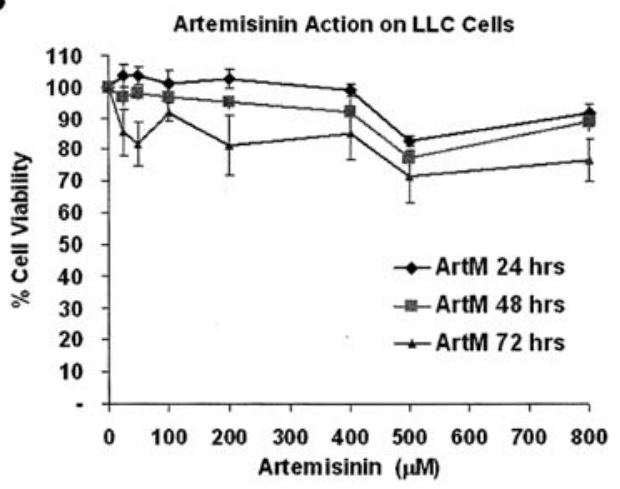

D

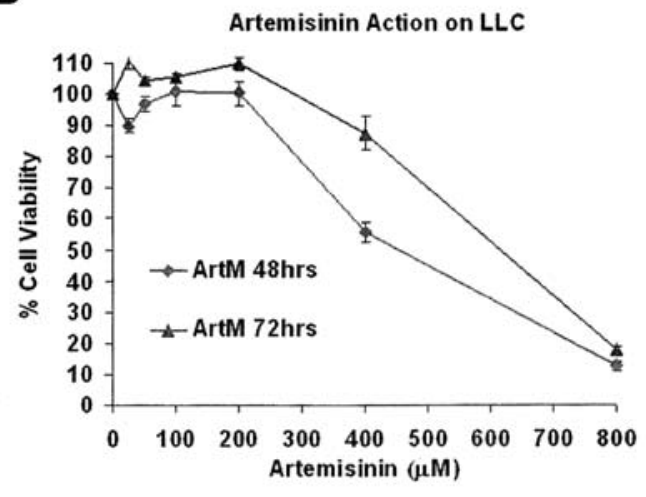

Figure 6. Plated dose response curves of artemesinin and artesunate against Lewis lung carcinoma cells show that the latter is a much more powerful anticancer agent than the former.

\section{Acknowledgments}

A grant from the Abramson Cancer Center of the University of Pennsylvania (PEM) provided partial financial assistance, as did the following: NIH-R01 5R01CA133470-02 (M.C.S.),
American Institute for Cancer Research \#AICR-03B024 (M.C.S.), the University of Pennsylvania Research Foundation (M.C.S.), and a pilot project support from 1P30 ES013508-02 awarded to M.C.S. (its contents are solely the responsibility of the authors and do not necessarily represent the official 
views of the NIEHS, NIH). The co-authors also wish to thank F. Duke, G.R. Hall, and E. Wang for experimental and bibliographic support. V.H. Mair, D. Barlow, and T. Ehrman advised on TCM botanical species and chemical composition.

\section{References}

1. Greenwood D: The quinine connection. J Antimicrob Chemother 30: 417-427, 1992

2. Jenab $M$ and Thompson LU: The influence of flaxseed and lignan on colon carcinogenesis and beta-glucuronidase activity. Carcinogenesis 17: 1343-1348, 1996.

3. Chen J, Hui E, Ip T and Thompson LU: Dietary flaxseed enhances the inhibitory effect of tamoxifen on the growth of estrogendependent human breast cancer $(\mathrm{MCF}-7)$ in nude mice. Clin Cancer Res 10: 7703-7711, 2004.

4. Kinniry P, Amrani Y, Vachani A, et al: Dietary flaxseed supplementation ameliorates inflammation and oxidative tissue damage in experimental models of acute lung injury in mice. J Nutr 136: 1545-1551, 2006.

5. Lee JC, Bhora F, Sun J, et al: Dietary flaxseed enhances antioxidant defenses and is protective in a mouse model of lung ischemia-reperfusion injury. Am J Physiol Lung Cell Mol Physiol 294: L255-L265, 2008.

6. Lee JC, Krochak R, Blouin A, et al: Dietary flaxseed prevents radiation-induced oxidative lung damage, inflammation and fibrosis in a mouse model of thoracic radiation injury. Cancer Biol Ther 8: 47-53, 2009.

7. Blouin G: Weeds of the woods: small trees and shrubs of the eastern forest. Nimbus, Halifax, 2004.

8. Mann J: Natural products in cancer chemotherapy: past, present and future. Nat Rev Cancer 2: 143-148, 2002.

9. Corson TW and Crews CM: Molecular understanding and modern application of traditional medicines: triumphs and trials. Cell 130: 769-774, 2007

10. Wink M: Bioprospecting: the search for bioactive lead structures from nature. In: Medicinal Plant Biotechnology: From Basic Research to Industrial Applications. Kayser O and Quax W (eds.) Wiley-VCH, Weinheim, pp97-116, 2007.

11. Abelson PH: Medicine from plants. Science 247: 513, 1990.

12. Johns T: With bitter herbs they shall eat it: Chemical ecology and the origins of human diet and medicine. University of Arizona, Tucson, 1990

13. Balter M: Plant science: Seeking agriculture's ancient roots Science 316: 1830-1835, 2007

14. McGovern PE: Uncorking the past: the quest for wine, beer, and other alcoholic beverages. University of California, Berkeley, 2009.

15. Dudley R: Ethanol, fruit ripening, and the historical origins of human alcoholism in promate frugivory. Integr Collab Biol 44: 315-325, 2004

16. Majno G: The healing hand: man and wound in the ancient world. Harvard University, Cambridge, 1975.

17. McGovern PE, Mirzoian A and Hall GR: Ancient Egyptian herbal wines. Proc Natl Acad Sci USA 106: 7361-7366, 2009.

18. Hartung U: Importkeramik aus dem dem Friedhof $U$ in Abydos (Umm el-Qaab) und die Beziehungen ägyptens zu Vorderasien im 4. Jahrtausend v. Chr. P. von Zabern, Mainz, 2001.

19. Owen T (trans.): Geoponika: Agricultural pursuits. London, printed for the author, 1805-1806.

20. Manniche L: An ancient Egyptian herbal. University of Texas, Austin, 1989.

21. Nunn J: Ancient Egyptian medicine. University of Oklahoma Norman, 1996.

22. McGovern PE, Zhang J, Tang J, et al: Fermented beverages of pre- and proto-historic china. Proc Natl Acad Sci USA 101: 17593-17598, 2004

23. Zhu YP: Chinese materia medica: chemistry, pharmacology, and applications. Harwood Academic, Amsterdam, 1998

24. Yan X, Zhou J and Xie G: Traditional chinese medicines: molecular structures: natural sources, and applications. Milne GWA (ed.) Ashgate, Aldershot, UK, 1999.

25. Shin S: In vitro effects of essential oils from the aerial parts of Artemisia annua L. against antibiotic-susceptible and -resistant strains of Salmonella typhimurium. Yakhak Hoechi 51: 355-360, 2007.

26. Brown GD, Liang GY and Sy LK: Terpenoids from the seeds of Artemisia annua. Phytochemistry 64: 303-323, 2003.
27. Ehrman TM, Barlow DJ and Hylands PJ: Phytochemical databases of Chinese herbal constituents and bioactive plant compounds with known target specificities. J Chem Inf Model 47: 254-263, 2007.

28. Harper D: Early Chinese medical literature: The Mawangdui medical transcripts. Kegan Paul International, London, 1998.

29. Li L-N, Zhang HD, Yuan SJ, Tian ZY, Wang L and Sun ZX: Differential sensitivity of colorectal cancer cell lines to artesunate is associated with expression of beta-catenin and E-cadherin. Eur J Pharmacol 588: 1-8, 2008.

30. Dell'Eva R, Pfeffer U, Vené R, et al: Inhibition of angiogenesis in vivo and growth of Kaposi's sarcoma xenograft tumors by the anti-malarial artesunate. Biochem Pharmacol 68: 2359-2366, 2004.

31. Berger TG, Dieckmann D, Efferth T, et al: Artesunate in the treatment of metastatic uveal melanoma - first experiences. Oncol Rep 14: 1599-1603, 2005.

32. Efferth T: Willmar Schwabe Award 2006: antiplasmodial and antitumor activity of artemisinin - from bench to bedside. Planta Med 73: 299-309, 2007.

33. Hou J, Wang D, Zhang R and Wang H: Experimental therapy of hepatoma with artemisinin and its derivatives: in vitro and in vivo activity, chemosensitization, and mechanisms of action. Clin Cancer Res 14: 5519-5530, 2008.

34. Wang Q, Wu LM, Li AY, et al: Experimental studies of antitumor effect of artesunate on liver cancer. Zhongguo Zhong Yao Za Zhi (China Journal of Chinese Materia Medica) 10: 707-720 (in Chinese), 2001

35. Chen HH, Zhou HJ, Wu GD and Lou XE: Inhibitory effects of artesunate on angiogenesis and on expressions of vascular endothelial growth factor and VEGF receptor KDR/flk-1. Pharmacology 71: 1-9, 2004.

36. Du J-H, Zhang H-D, Ma Z-J and Ji K-M: Artesunate induces oncosis-like cell death in vitro and has antitumor activity against pancreatic cancer xenografts in vivo. Cancer Chemother Pharmacol: published on-line August 19, 2009.

37. Michaelis M, Kleinschmidt MC, Barth S, et al: Anti-cancer effects of artesunate in a panel of chemoresistant neuroblastoma cell lines. Biochem Pharmacol: published on-line August 19, 2009.

38. Zhou HJ, Wang WQ, Wu GD, et al: Artesunate inhibits angiogenesis and downregulates vascular endothelial growth factor in chronic myeloid leukemia K562 cells. Vasc Pharmacol 47: 131-138, 2007

39. Efferth T, Romero MR, Wolf DG, Stamminger T, Marin JJ and Marschall M: The antiviral activities of artemisinin and artesunate. Clin Infect Dis 47: 804-811, 2008.

40. Efferth T, Dunstan H, Sauerbrey A, Miyachi H and Chitambar CR: The anti-malarial artesunate is also active against cancer. Int J Oncol 18: 767-773, 2001.

41. Moore JC, Lai H, Lim JR, et al: Oral administration of dihydroartemisinin and ferrous sulfate retarded implanted fibrosarcoma growth in the rat. Cancer Lett 98: 83-87, 1995.

42. Chen HH, Zhou HJ and Fang X: Inhibition of human cancer cell line growth and human umbilical vein endothelial cell angiogenesis by artemisinin derivatives in vitro. Pharmacol Res 48: 231-236, 2003.

43. Yamachika E, Habte $\mathrm{T}$ and Oda D: Artemisinin: an alternative treatment for oral squamous cell carcinoma. Anticancer Res 24: 2153-2160, 2004.

44. Disbrow GL, Baege AC, Kierpiec KA, et al: Dihydroartemisinin is cytotoxic to papillomavirus-expressing epithelial cells in vitro and in vivo. Cancer Res 65: 10854-10861, 2005.

45. Shoemaker M, Hamilton B, Dairkee SH, Cohen I and Campbell MJ: In vitro anticancer activity of twelve Chinese medicinal herbs. Phytother Res 19: 649-651, 2005.

46. Lai H and Singh NP: Oral artemisinin prevents and delays the development of 7,12-dimethylbenz[a] anthracene (DMBA)induced breast cancer in the rat. Cancer Lett 231: 43-48, 2006.

47. Singh NP: Case report of a pituitary macroadenoma treated with artemether. Integr Cancer Ther 5: 391-394, 2006.

48. Efferth T, Giaisi M, Merling A, Krammer PH and Li-Weber M: Artesunate induces ROS-mediated apoptosis in doxorubicinresistant T leukemia cells. PLoS One 2: e693, 2007.

49. Li N, Mao Y, Deng C and Zhang X: Separation and identification of volatile constituents in Artemisia argyi flowers by GC-MS with SPME and steam distillation. J Chromatogr Sci 46: 401-405, 2008.

50. Sun J: In vitro anticancer activity of aqueous extracts and ethanol extracts of fifteen traditional Chinese medicines on human digestive tumor cell lines. Phytother Res 21: 1102-1104, 2007. 
51. Li PCH, Lam E, Roos WP, Zdzienicka MZ, Kaina B and Efferth T: Artesunate derived from traditional Chinese medicine induces DNA damage and repair. Cancer Res 68: 4347-4351, 2008.

52. Chen H, Sun B, Pan S, Jiang H and Sun X: Dihydroartemisinin inhibits growth of pancreatic cancer cells in vitro and in vivo. Anticancer Drugs 20: 131-140, 2009.

53. Ramacher M, Umansky V and Efferth T: Effect of artesunate on immune cells in ret-transgenic mouse melanoma model. Anticancer Drugs 20: 910-917, 2009.

54. Efferth T, Bernakis A, Romero MR, et al: Enhancement of cytotoxicity of artemisinins toward cancer cells by ferrous iron. Free Radic Biol Med 37: 998-1009, 2004.

55. Adams M, Efferth T and Bauer R: Activity-guided isolation of scopoletin and isoscopoletin, the inhibitory active principles towards CCRF-CEM leukaemia cells and multi-drug resistant CEM/ADR5000 cells, from Artemisia argyi. Planta 72: 862-864, 2006.

56. SciFinder Scholar, URL: http://www.cas.org/SCIFINDER/ SCHOLAR/. Chemical Abstract Services, American Chemical Society.

57. Kirk-Othmer Encyclopedia of Chemical Technology, 2004. Wiley-Interscience, Hoboken, $\mathrm{NJ}$; also available on-line at http://mrw.interscience.wiley.com/emrw/9780471238966/home/

58. Dr Duke's Phytochemical and Ethnobotanical Databases. URL: http://www.ars-grin.gov/duke/ Agricultural Research Service, US Department of Agriculture, Beltsville, MD.
59. Amber Research Laboratory of Vassar College, chemical database, URL: http://cima.ng-london.org.uk/arl/ Maintained by the National Gallery, London.

60. Zheng X, Deng C, Song G and Hu Y: Comparison of essential oil composition of Artemisia argyi leaves at different collection times by headspace solid-phase microextraction and gas chromatography-mass spectrometry. Chromatographia 59: 729-732, 2004.

61. Deng C, Mao Y, Hu F and Zhang X: Development of gas chromatography-mass spectrometry following microwave distillation and simultaneous headspace single-drop microextraction for fast determination of volatile fraction in Chinese herb. J Chromatogr 1152: 193-198, 2007.

62. Wang W and El-Deiry WS: Bioluminescent molecular imaging of endogenous and exogenous p53-mediated transcription in vitro and in vivo using an HCT116 human colon carcinoma xenograft model. Cancer Biol Ther 2: 196-202, 2003.

63. Lambright ES, Amin K, Wiewrodt R, et al: Inclusion of the herpes simplex thymidine kinase gene in a replicating adenovirus does not augment antitumor efficacy. Gene Ther 8: 946-953, 2001.

64. Wang W and El-Deiry WS: Restoration of p53 to limit tumor growth. Curr Opin Oncol 20: 90-96, 2008.

65. El-Deiry WS, Tokino T, Velculescu VE, et al: WAF1, a potential mediator of p53 tumor suppression. Cell 75: 817-825, 1993. 